\title{
Full term secondary abdominal pregnancy in a Jehovah's witness: A case report ${ }^{*}$
}

\author{
Betrand Obi Nwosu ${ }^{1 \#}$, Anthony Osita Igwegbe ${ }^{1}$, George Uchenna Eleje $^{1}$, \\ Joseph O. Ugboaja ${ }^{1}$, Izuchukwu Stanley Etoniru', Ochonma Amobi Egwuonwu², \\ Livinus Okor ${ }^{1}$
}

\author{
${ }^{1}$ Department of Obstetrics and Gynaecology, Nnamdi Azikiwe University Teaching Hospital, Nnewi, Nigeria; \\ \#Corresponding Author: drobinwosu@yahoo.com \\ ${ }^{2}$ Department of Surgery, Nnamdi Azikiwe University Teaching Hospital, Nnewi, Nigeria
}

Received 16 October 2012; revised 20 November 2012; accepted 29 November 2012

\begin{abstract}
We describe a rare case of full term abdominal pregnancy in a Jehovah's witness patient; she underwent laparotomy successfully without blood transfusion. Despite their belief regarding transfusion, Jehovah's witnesses may not necessarily have a higher morbidity or mortality rate following a complex obstetric surgery as seen in the present case.
\end{abstract}

Keywords: Abdominal Pregnancy; Jehovah Witness; Blood Transfusion; Durable Power of Attorney; Extra-Uterine Placentation

\section{INTRODUCTION}

Abdominal pregnancy is a variety of ectopic pregnancy and may be defined as intraperitoneal implantation exclusive of tubal, intraligamentous or ovarian implantation. It is a rare obstetric emergency and its occurrence in a Jehovah's Witness patient is very challenging because they are known worldwide for their refusal of the acceptance of blood and blood products [1]. The unique aspects of these beliefs can pose management challenges to health care providers in addition to ethical and medicolegal dilemmas [1,2]. Modifications of standard transfusion practices may be necessary to respect the beliefs of the Jehovah's Witnesses patient and this may seem to be a hindrance to the optimal care of a patient. We describe here a 35-year-old Jehovah's Witness patient with full term secondary abdominal pregnancy who had a laparotomy with a live baby, which to the best of our knowledge is the first of such a case in Jehovah's Witness patient reported in Nigeria.

*Competing interests: the authors declare that they have no competing interests.

\section{CASE PRESENTATION}

A 35-year old woman, primigravida, came to our antenatal clinic at 38 completed weeks. She had been investigated and treated earlier for 5 years of infertility at our hospital, and was already receiving antenatal care at another tertiary hospital which is about 200 kilometers from our hospital. She presented to our antenatal clinic due to industrial action at her booked tertiary hospital.

She came with an ultrasound report that showed a viable singleton at 34 week gestation in oblique lie and cephalic presentation which was done four weeks prior. The fetus was noted to have genitourinary tract abnormalities (cystic left kidney and irregular bladder outline) and omphalocoele. A co-existing fibroid mass in the mother was also noted. She had pelvic pain at 10 weeks of gestation and continued to have vaginal spotting up to the 18th week for which she received intramuscular progestogen once weekly which she obtained from a friend and used as self medication. Otherwise the pregnancy had been uneventful. She reported that she had not had any contractions but had felt a lot of fetal movement. Physical examination revealed a young healthy-looking woman in no obvious distress. She was afebrile, not pale and anicteric. She was neither dehydrated nor had pedal oedema. Blood pressure was 120/70 mmHg; pulse rate was 76 beats per minute. Symphysio-fundal height was $31 \mathrm{~cm}$ and the "uterus" harboured a viable singleton in longitudinal lie, cephalic presentation. The haemoglobin and haematocrit values were $11 \mathrm{~g} / \mathrm{dl}$ and 33\% respectively. She was admitted for elective "caesarean section" the next day. Her urine analysis showed no significant protein or glucose; blood group was O Rhesus D positive; genotype AA; venereal disease research laboratory test was non reactive. Two units of whole blood were grouped and saved. The paediatric surgery team was invited in view of the ultrasound findings of fetal malformation.

She eventually had laparotomy with the paediatric sur- 
gery team in attendance using a midline subumbilical incision under spinal anaesthesia. Intraoperative findings included: a bulky uterus, a live female baby with pseudoprune belly syndrome (APGAR 6/1, 8/5), placenta that was attached to the posterior wall of the uterus, left broad ligament and adnexa (Figure 1). The left fallopian tube was incorporated into the placental attachment and the ovary on that side was not visualized. The right fallopian tube and ovary were normal. The baby was delivered through an incision on hypertrophic fetal membranes and the placental attachments were only defined after some attempts at delivering it. There was massive haemorrhage during which time the general surgery team was invited, and patient adamantly refused cross matching of blood transfusion.

It was subsequently removed as much as could be safely done with the assistance of the general surgeon. The left tube, left ovary and left broad ligament were removed with the placenta and haemostasis was secured. The peritoneum and abdominal wall were closed in layers. The estimated blood loss was 3.0 litres. She received 2.5 litres of Haemacel intraoperatively and had no blood transfusion. She was also placed on oxygen therapy. There was no active bleeding at the end of the procedure. The immediate post operative condition was satisfactory. She remained haemodynamically stable until an hour post operatively when the blood pressure was noted to be $80 / 30 \mathrm{mmHg}$, pulse rate of 102 beats/minute and respiretory rate of 22 cycles per minute. She received intravenous hydrocortisone $200 \mathrm{mg}$, intravenous normal saline 1 litre over 20 minutes, and oxygen was continued. During this time the patient's husband refused blood transfusion. The resuscitation was successful.

She had a second episode of haemodynamic instability about three hours after the first and was resuscitated again. Her urinary output was adequate throughout this period. Thereafter she had steady recovery on the post operative prescription: intravenous antibiotics (ampicillin/ sulbactam $1.5 \mathrm{~g} 12$ hourly for forty-eight hours, metronidazole $500 \mathrm{mg} 8$ hourly for 48 hours; intravenous fluid $0.9 \%$ normal saline one litre to alternate with $5 \%$ dextrose in water one litre 8 hourly for 48 hours). During this time she was on nil per orum until bowel sounds returned. She also had adequate parenteral analgesia and fluid input and output were monitored. Methotrexate was not required in the postoperative period. By the second post operative day, her bowel activity had fully returned and she was commenced on graded oral sips. Her haemoglobin concentration and haematocrit at the time were $3.7 \mathrm{~g} / \mathrm{dl}$ and $11 \%$ respectively. She was placed on subcutaneous erythropoietin (Epoietin beta) 4000 units three times a week for one week. Her parenteral drugs were converted to oral antibiotics, analgesics and haematinics.

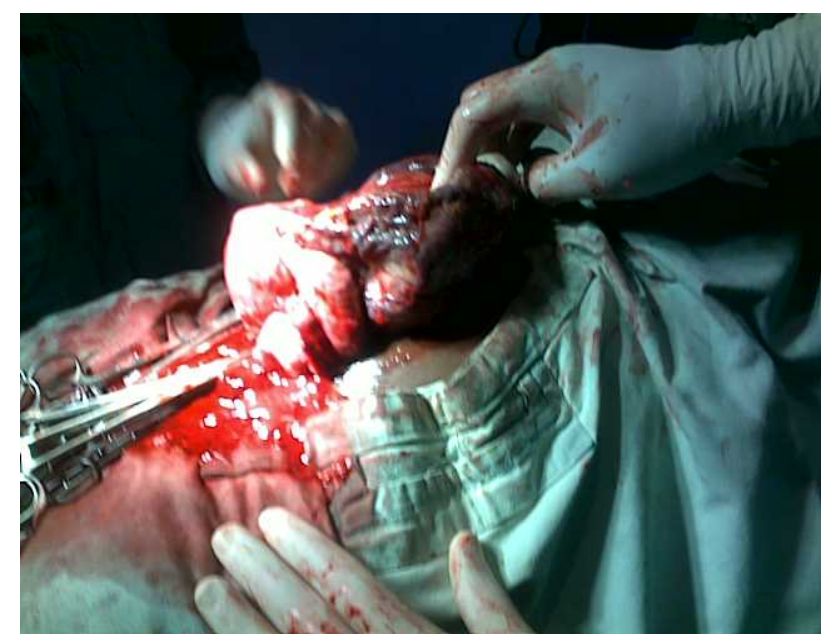

Figure 1. The relationship between the placenta and the uterus.

She was discharged on the 8th post operative day in good condition, though pale with packed cell volume of $15 \%$. At discharge, the patient has established optimal lactation. She was given oral haematinics for 6 weeks on discharge. Her post natal visit two weeks after discharge revealed a packed cell volume of 34\%. Mother and baby were finally discharged home on day ten [3].

\section{DISCUSSION}

Jehovah's Witnesses number 7.4 million in the world [4]. Comparatively, this religious community is not very common in Nigeria with an estimated number of 330,316 or $0.20 \%$ of Nigerian population [4]. Nevertheless, medical practitioners in Nigeria will at some point encounter these patients and should be prepared to manage them under various circumstances. Honouring their beliefs can create challenging medical and surgical issues especially when it is not in favour of the principle of beneficence and conflicts with best medical and surgical practice.

The blood ban forbids them from accepting transfusion of allogenic whole blood and its' components which include red blood cell concentrates, white blood cells, plasma and platelets [1,2].

Most abdominal pregnancies implant in the posterior cul de sac, on the posterior aspect of the uterus and on the fundus as in our present case [5]. This was the case in our patient. On rare occasions, more hazardous implantations have been reported on the liver, spleen, and diaphragm [5].

The management of advanced abdominal pregnancy as in our case includes the issue of removal or leaving in-situ placenta which may have implanted into a major intrabdominal blood vessel which may entail extensive amount of placenta separation. With this, the resultant blood loss can be quite massive and life threatening.

Thus, treatment with recombinant human erythropoi- 
etin (RHuEPO) is a valuable adjunct in Jehovah's Witness patients especially after surgery. In our case, the erythropoetin was started at 4000 units three times weekly for one week. A baseline haematocrit was obtained, and this was repeated one week later. At the end of two weeks, there should be a response to the therapy as assessed by the haematocrit level. The haematocrit goal was achieved such that the haematocrit was 34\% three weeks after surgery. When erythropoetin is administered, the patient should be taking iron supplementation two or three times daily along with folic acid. All these were applied to our patient.

Interestingly, erythropoietin has been shown to significantly increase the haematocrit level with a $50 \%$ reduction in the need for blood transfusions [6] and this is acceptable to many Jehovah's Witnesses. The administration of ferrous sulphate, folic acid and recombinant erythropoietin helped to maintain the haemoglobin during the post operative period and enhanced the immediate post-operative haematocrit levels to $15.0 \%$. These measures are important, as a study conducted among patients who declined blood transfusion for religious reasons has shown that morbidity and mortality rates increased dramatically when the haemoglobin concentration decreased below $6 \mathrm{~g} / \mathrm{dL}$ [7]. Kitchens [8] conducted a review of 16 reports of the surgical outcome of series in the Jehovah's Witness patients who were not given blood despite undergoing 1404 surgical procedures that normally would necessitate transfusion. The primary cause of death was lack of blood in only $0.6 \%$ of patients and a contributor to death in another $0.85 \%$ of patients. However, a number of additional strategies, including acute normovolaemic haemodilution, intra-operative blood salvage and reinfusion, iron and folate supplementation could also be utilized to avoid blood transfusion.

In a previous case report of secondary abdominal pregnancy in a Jehovah's Witness patient by Shaw and Ezenwa [9], the patient died about one day after the surgery following transfer to other facility for hyperbaric oxygen therapy. However, our patient's survival could be because of the multidisciplinary approach applied in the management without need for patient referral, coupled with the involvement of the general surgery team where meticulous measures were taken to identify and secure haemostasis at the end of surgery. This was possible because the managing hospital was a tertiary hospital. There were available, haemacele in our hospital at the time of surgery which was used as a plasma expander. Subsequently, there were no episodes of post operative vaginal bleeding.

Placental management following an advanced abdominal pregnancy has shifted towards a non-surgical approach of leaving the placenta in situ [3]. Active attempts to surgical removal of the placenta may be asso- ciated with severe haemorrhage and excessive maternal morbidity or mortality $[3,10]$. In our case, the placenta was found to have already separated intra-operatively and this necessitated the removal of the placenta albeit meticulously. Similarly, in a previous case report of advanced abdominal pregnancy in Nnewi, placenta was removed intra-operatively without posing any threat [3]. Nevertheless, leaving the placenta in situ is not, however, without potential maternal risks, including a prolonged resorption period, delayed placental haemorrhage, bowel obstructtion and peritonitis $[3,10]$. In view of the large placental mass in the case under discussion, we elected to remove the placenta as much as possible without the need for methotrexate while waiting for the slow spontaneous absorption of the residual placental mass.

Postpartum haemorrhage (PPH) often results in iron deficiency anaemia, puerperal sepsis and pituitary infarcttion (Sheehan's syndrome) with associated poor lactation [11]. Fortunately, despite the severe blood loss, our patient never had features of Sheehan's syndrome, but only had anaemia which was successfully managed with erythropoietin and haematinics without blood transfusion.

A mentally balanced adult patient like ours has an absolute right to refuse medical treatment. In our case, the husband and the patient gave written consent and the patient submitted the durable power of attorney (DPA) card. The DPA card is very relevant in every adult Jehovah's Witness patient being managed in a hospital because it absolve all doctors and the hospital from any liabilities should the outcome be adverse as a result of refusal of blood transfusion. To this end, it is a good practice that every medical practitioner request from any adult Jehovah's Witness patient his or her DPA card before embarking on surgical or medical procedure that might require blood transfusion.

\section{CONCLUSION}

This case is like any other case of abdominal pregnancy with one major difference. This difference lies not in the biological or science aspect, but social believes which has drastic impact on us, the health care providers. This case illustrates how a high risk obstetric entity and surgery were carried out successfully in a Jehovah's witness patient. Building a good rapport with the patient and maintaining effective, honest communication regarding transfusion options without any element of coercion is the cornerstone in the management of these patients. Rather than discriminating against Jehovah's witness patients because of their beliefs, alternative modern medical care acceptable to these patients can be used to support blood volume and haemostatic function, during the course of treatment of serious life threatening blood-demanding issues in obtstetrics and gynaecology. To provide optimal antenatal and intraparturm care for a Jehovah's Witness, 
the obstetrician should be well versed in the management and available alternatives for these types of cases. The patient should deliver at a tertiary care center with an in-house obstetrician, surgeons, paediatricians and anaesthesiologist available. It is disappointing that despite a pregnancy secondary to prolonged infertility, the diagnosis was not made in a timely manner, although the outcome for the mother and child were excellent. Attention to the basic principles of pregnancy imaging is central to the prenatal detection of this potentially lethal condition, and the distraction of scanning the intrauterine contents should not prevent assessment of the pregnancy location.

\section{ACKNOWLEDGEMENTS}

The woman whose story is told in this case report signed permission for its publication. Also Dr. Etoniru I.S. and Dr. Egwuonwu O.A. of Nnamdi Azikiwe University Teaching Hospital, Nnewi for their contributions.

\section{REFERENCES}

[1] Hughes, D.B., Ullery, B.W. and Barie, P.S. (2008) The contemporary approach to the care of Jehovah's witnesses. The Journal of Trauma, 65, 237-247. doi:10.1097/TA.0b013e318176cc66

[2] Gyamfi, C., Gyamfi, M.M. and Berkowitz, R.L. (2008) Ethical and medicolegal considerations in the obstetric care of a Jehovah's Witness. Obstetrics \& Gynecology, 2003, 102, 173-180. doi:10.1016/S0029-7844(03)00236-9

[3] Eleje, G.U., Ezebialu, I.U., Okpala, B.C., Okolie, V.E. and Onyegbule, O.A. (2011) Advanced abdominal pregancy in a diabetic multipara is delivery of the placenta always a problem? Afrimedic Journal, 2, 32-33.
[4] 2011 Service Year Report of Jehovah’s Witnesses Worldwide (2012) 2012 yearbook of Jehovah’s witnesses. www.watchtower.org

[5] Bertrand, G., Ray, C.L., Simard-Émond, L., Dubois, J. and Leduc, L. (2009) Imaging in the management of abdominal pregnancy: A case report and review of the literature. Journal of Obstetrics and Gynaecology Canada, 31, 57-62.

[6] Corwin, H.L., Gettinger, A., Rodriguez, R.M., Pearl, R.G., Gubler, K.D., Enny, C., Colton, T. and Corwin, M.J. (1999) Efficacy of recombinant human erythropoietin in the critically ill patient: A randomized, double-blind, placebo-controlled trial. Critical Care Medicine, 27, 23462350. doi:10.1097/00003246-199911000-00004

[7] Carson, J.L., Noveck, H., Berlin, J.A. and Gould, S.A. (2002) Mortality and morbidity in patients with very low postoperative $\mathrm{Hb}$ levels who decline blood transfusion. Transfusion, 42, 812-818. doi:10.1046/j.1537-2995.2002.00123.x

[8] Kitchens, C.S. (1993) Are transfusions overrated? Surgical outcome of Jehovah's witnesses. American Journal of Medicine, 94, 117-119. doi:10.1016/0002-9343(93)90171-K

[9] Shaw, H.A. and Ezenwa, E. (2000) Secondary abdominal pregnancy in a Jehovah's witness. Southern Medical Journal, 93, 898-900.

[10] Roberts, R.V., Dickinson, J.E., Leung, Y. and Charles, A.K. (2005) Advanced abdominal pregnancy: Still an occurrence in modern medicine. Australian and New Zealand Journal of Obstetrics and Gynaecology, 45, 518-521. doi:10.1111/j.1479-828X.2005.00489.x

[11] Leduc, D., Senikas, V. and Lalonde, A.B. (2009) Active management of the third stage of labour: Prevention and treatment of postpartum haemorrhage. Journal of Obstetrics and Gynaecology Canada, 31, 980-993. 